\title{
Writing Textbook Supplements
}

\author{
Edward M. Scahill* \\ Department of Economics and Finance, the University of Scranton, USA \\ *Corresponding author: edward.scahill@scranton.edu
}

Received June 21, 2014; Revised September 25, 2014; Accepted October 08, 2014

\begin{abstract}
Accuracy checking and writing ancillary materials such as test banks and instructor's manuals, are obscure but important components of college textbook packages. This article provides an overview of the supplement writing process based on the author's experience writing for several economics textbooks.
\end{abstract}

Keywords: economics textbooks, supplementary materials

Cite This Article: Edward M. Scahill, “Writing Textbook Supplements.” Journal of Finance and Economics, vol. 2, no. 5 (2014): 199-201. doi: 10.12691/jfe-2-5-11.

\section{Introduction}

An obscure segment of the college textbook market is the writing of ancillary materials, or textbook supplements. Although no instructor bases the selection of a textbook on the text's end-of-chapter problems or instructor's manual, supplements are integral parts of the package of materials publishers offer to textbook adopters. Authors and publishers value supplement writers who do their work well and in a timely manner. The following comments are based on the author's experience as an accuracy checker and supplement writer for college economics textbooks published by Pearson Education, Inc. [1,2,3].

\section{Supplement Writing: An Overview}

Publishers use various means to identify potential writers of textbook supplements. The following are the most common.

a. "House calls" - Although personnel cutbacks in recent years have reduced the number of publishers' representatives (reps) who make "house calls" campus visits to instructors' offices - the visits are an important means for recruiting supplement writers. The visits typically involve inquiries regarding textbook needs for the coming semester(s). Reps may also ask instructors if they are considering writing a textbook. If the rep's publisher has a new or revised textbook in the planning or writing stage she may ask the instructor if he is interested in reviewing one or more chapters of the book. Accuracy checking is often the first step in becoming a supplement writer. If an accuracy checker does good work, other assignments may follow.

b. Focus groups - publishers occasionally organize focus groups at national (American Economic Association) or regional (e.g., the Eastern and Southern Economic Associations) meetings of professional organizations. Solicitations for focus group participation are sent to members of the associations prior to their annual meetings. Group members meet to discuss a proposed or in-progress textbook. Focus group members who interact well with group participants, including authors, and who provide useful feedback are candidates for accuracy checking assignments.

\section{c. Prior contacts with publishers and authors}

\subsection{Accuracy Checking}

Accuracy checking consists of a review of one or more chapters of a text for errors. Several checkers, including authors, are typically used for each chapter. Although checkers may be asked to report on spelling or grammatical errors, publishers typically use other personnel for this purpose. Economics instructors are expected to concentrate on areas of their expertise: reviewing graphs, numerical calculations, end-of-chapter problems and their solutions, etc. Those who handle their accuracy checking duties well may be asked to take on other assignments, including writing instructor's manuals, study guides, and test bank problems and questions. Supplement writers may also be asked to contribute material included within texts; for example, sidebars and end-of-chapter problems. Publishers cast a wide net when they employ accuracy checkers and supplement writers. For example, the $5^{\text {th }}$ edition of Economics by R. Glenn Hubbard and Anthony Patrick O’Brien, acknowledged the contributions of the following (some names appear on more than one list):

Accuracy review board members....9

Reviewers (accuracy checkers).....26

Total.............................35

The textbook also acknowledged the efforts of individuals who contributed to the previous four editions:

Class testers........................18

Accuracy review board members...56

Reviewers (accuracy checkers).......581

Total..............................655

In addition to ensuring accuracy, employing checkers provides a marketing opportunity for the publisher. 
Presumably, the checkers will consider adopting the publisher's textbook for their own courses.

\subsection{Accuracy Checking Role Model}

Checkers implicitly compare the compensation for reviewing a textbook chapter with the opportunity cost of their time. The resulting reviews may contain valid comments, but many comments refer to easily identified errors that other reviewers will have found as well. The best candidates for other writing assignments are checkers who discover errors that others don't; for example, a mistake in the title of a magazine or journal article that appears in a footnote, or an error in a quotation. From the publisher's standpoint, the ideal accuracy checker takes his assignment seriously and personally. For the checker, the satisfaction from finding an obscure error is as important as the financial compensation for the assignment. A useful, admittedly whimsical, example of a role model can be found in an episode of the television program Monk.

Adrian Monk, portrayed by Tony Shalhoub, is a skilled detective employed by the San Francisco Police Department. But Monk has developed an extreme obsessive-compulsive disorder and numerous phobias that compel him to hire an assistant and seek psychiatric therapy. In one episode Monk is fired from his job and forced to interview with a magazine publisher for a job as a "fact checker." The interview starts badly as Monk fidgets in his chair and tells the interviewer an unfunny joke. But then the interview takes another turn:

Molly Hagan as Ms. Lennington (M.L.)

Tony Shalhoub at Adrian Monk (A.M.)

M.L.: I see you worked as a consultant for the police department. That must have been very exciting. Have you done any fact checking?

A.M.: Ah, no ma'am - unless you count this morning.

M.L.: What happened this morning?

A.M. Well, Sharona took me to the library to look at some back issues of your magazine...found a few mistakes. Page 32: "the building was decimated." Technically incorrect - Decimate means to reduce by one-tenth...decimate.

M.L.: Wow (looking through pages of corrections). And you did all this this morning in the library? How many magazines did you read?

A.M.: Just that one.

M.L.: Wow!

A.M.: It's a gift...and a curse.

Source: [4]

Much to Sharona's (Monk's nurse and assistant) amazement, Monk lands the job. Predictably, by the end of the episode he solves a murder and is rehired by the San Francisco Police Department.

\subsection{What Publishers Want}

A sophisticated division of labor is employed by textbook publishers. Different individuals, some of whom may reside in foreign countries, perform different tasks. Supplement writers will have contact with one or more editors and the author(s) but generally will not interact with the others involved in the editing and publishing process. Employing a division of labor has obvious advantages but can be the source of mistakes that checkers are left to find. For example, a graphic artist - with little knowledge of economic theory - in a foreign country can be told to draw a graph that includes an indifference curve and a budget line, with the latter being tangent to the former. Failure to draw the graph correctly would result in a serious error. Obviously, finding and correcting errors is essential. But publishers prize other characteristics in their supplement writers. Whether assignments involve accuracy checking or writing supplementary materials, publishers and textbook writers have an implicit list of attributes.

\section{4. (a) "We want it by last Tuesday, but yesterday is acceptable."}

Economics instructors are the ultimate source for supplement writing and accuracy checking. Although instructors usually will have the most time to spend on such assignments during the summer months, authors and publishers have their own schedules, schedules that often do not conform to an academic calendar. The deadlines for writing assignments for supplements often occur during the fall months. Publishers want to have their textbooks as well as ancillary materials in print early in the calendar year so the materials can be marketed to potential adopters. Due dates for writing assignments can conflict with teaching and exam schedules. Supplement writers have to work around these schedules to finish their work on time.

\section{5. (b) Remember Whose Names are on the Cover}

Textbook authors have their own teaching philosophies that determine the topics covered and examples used. Accuracy checkers are expected to check accuracy; suggestions to state a problem differently or to add a section or chapter on a special topic may not be accepted. Checkers should understand that the authors' opinions must trump their own.

\section{6. (c) How to Get Fired}

Other than death and taxes there may be few things certain in life, but another certainty is that a supplement writer who fails to submit his or her work on time will not be asked to submit anything else. Imagine a (realistic) scenario: a textbook has been written and checked, test banks updated but an instructor's manual or study guide is half-finished. The supplement writer has placed the authors and publisher in a bind. At this late date it is difficult, if not impossible, to find another writer who can finish the job without significant delay.

\section{7. "We'll Fix It in the Next Edition"}

The most diligent checkers will occasionally fail to find errors, some of which pass through more than one edition of the textbook. For example, in Economics one end-ofchapter problem concerned the market for taxi rides in New York City. The number of rides was assumed to be limited due to the restriction on taxi medallions in the city. A graph depicted the demand and supply of taxi rides with the medallion restriction and what the equilibrium price and quantity would be without the restriction. Students were asked a series of questions regarding the graph. One 
of the questions involved the calculation of consumer surplus, producer surplus and deadweight loss areas depicted in the graph. Answers to all of the end-of-chapter questions were written by a writer (not one of the authors) and included in the instructor's manual (most of which was written by yet another writer). The responses were accuracy checked by yet another writer. The problem and answers survived through three editions of the textbook, but in reviewing the calculations for consumer and surplus for the $4^{\text {th }}$ edition, one of the authors realized that the responses given in the instructor's manual were inconsistent with his own calculations. The error was finally discovered and corrected - but not in time for the $4^{\text {th }}$ edition.

\subsection{Some Supplement Writing is Creative}

The format of an instructor's manual and a study guide can vary as much as the format of the textbooks they are packaged with. For example, an instructor's manual may summarize the material in the textbook, include answers to end-of-chapter problems and offer some advice on presenting certain topics in the classroom. The instructor's manual for Economics and other textbooks by the same authors [2,3] include these features, but also sidebars similar to those found in the textbook. For example, the texts include multiple Solved Problem and Making the Connection sidebar features in each chapter. Solved Problems use a step-by-step process to illustrate the process of solving an economic problem related to one of the textbook chapter's learning objectives. Most chapters contain two Solved Problems but as many as seven learning objectives. The instructor's manuals (one each for microeconomics and macroeconomics) include additional Solved Problems for each of the other learning objectives. Making the Connection refers to contemporary real-world references to economic concepts that appear in newspaper or magazine articles. Additional features included in the instructor's manuals include Teaching Tips and Economics in Your Life. Writing for the extra features requires an extensive search for relevant references from newspaper, magazine and journal articles. The best of these features illustrate the textbook's learning objectives in a manner that students find interesting, and are consistent with the writing style used by the textbook author(s).

\subsection{A Not Entirely Thankless Job}

There may be no glory in writing supplements for textbooks, but there is the satisfaction of doing a job well. Being able to avoid teaching summer courses is a bonus. For those with some "Monk" in their psyches this can be satisfaction enough.

\section{Acknowledgement}

Lena Buonanno, Executive Development Editor for Pearson Education, Inc., provided valuable insight regarding the process used by publishers to select supplement writers.

\section{References}

[1] Hubbard, R.G. and A.P. O'Brien, Economics (5 ${ }^{\text {th }}$ ed.), Pearson Education, Inc., Boston, 2015.

[2] Hubbard, R.G., A.P. O’Brien and M. Rafferty, Macroeconomics, Pearson Education, Inc., Boston, 2012.

[3] Hubbard, R. G. and A.P. O'Brien, Money, Banking and the Financial System (2 ${ }^{\text {nd }}$ ed.), Pearson Education, Inc., Boston, 2014.

[4] USA Network, Universal Studios. Television. "Mr. Monk Gets Fired." Monk. July 16, 2004. 